University of Nebraska - Lincoln

DigitalCommons@University of Nebraska - Lincoln

January 1991

\title{
Patterns of Appraisal and Coping Across Different Stressor Conditions Among Former Prisoners of War With and Without Posttraumatic Stress Disorder
}

\author{
John A. Fairbank \\ Research Triangle Institute, Research Triangle Park, North Carolina \\ David J. Hansen \\ University of Nebraska-Lincoln, dhansen1@unl.edu \\ James M. Fitterling \\ University of Mississippi Medical Center
}

Follow this and additional works at: https://digitalcommons.unl.edu/psychfacpub

Part of the Psychiatry and Psychology Commons

\footnotetext{
Fairbank, John A.; Hansen, David J.; and Fitterling, James M., "Patterns of Appraisal and Coping Across Different Stressor Conditions Among Former Prisoners of War With and Without Posttraumatic Stress Disorder" (1991). Faculty Publications, Department of Psychology. 302.

https://digitalcommons.unl.edu/psychfacpub/302
}

This Article is brought to you for free and open access by the Psychology, Department of at DigitalCommons@University of Nebraska - Lincoln. It has been accepted for inclusion in Faculty Publications, Department of Psychology by an authorized administrator of DigitalCommons@University of Nebraska - Lincoln. 


\title{
Patterns of Appraisal and Coping Across Different Stressor Conditions Among Former Prisoners of War With and Without Posttraumatic Stress Disorder
}

\author{
John A. Fairbank \\ Research Triangle Institute \\ Research Triangle Park, North Carolina \\ James M. Fitterling \\ Jackson Veterans Affairs Medical Center \\ and University of Mississippi Medical Center
}

David J. Hansen

West Virginia University

\begin{abstract}
Little is known about how survivors of extreme events cope with traumatic memories and subsequent negative life experiences. The present study compared (a) repatriated prisoners of war (RPWs) from World War II (WW II) with chronic posttraumatic stress disorder (PTSD), (b) RPWs without PTSD, and (c) noncombat veterans on measures of general psychological functioning, appraisal, and coping. Appraisal and coping were assessed under 2 stressor conditions: memories of war/captivity and recent negative life events. RPWs with PTSD reported poorer general psychological functioning; significantly less control over memories of WW II; and more frequent use of self-isolation, wishful thinking, self-blame, and social support in an effort to cope with these memories than did the 2 comparison groups. Fewer between-groups differences were found for the recent stressor condition. Findings are discussed in terms of factors that may explain the perseverance of coping difficulties associated with PTSD.
\end{abstract}

Distressing and intrusive recollection of extreme events is a primary characteristic of posttraumatic stress disorder (PTSD), which, in the active memory of the survivor, serves as a chronic stressor that requires ongoing coping efforts (Green, Lindy, \& Grace, 1988). A major challenge facing clinicians who treat individuals with chronic PTSD is the development of intervention strategies that meet the coping demands of distressing traumatic memories. Yet little is known about how individuals who have survived extreme events appraise and cope with memories long after the occurrence of the events or about how trauma survivors cope with other more recent negative life experiences. Basic information on resilient and ineffective coping among survivors of extreme events is needed to guide clinicians in the development of efficacious interventions for PTSD (see Elder \& Clipp, 1989; Fairbank \& Nicholson, 1987).

Coping has been defined as the processes individuals use to modify adverse aspects of their environment as well as to minimize internal threat induced by stress (Fleming, Baum, \& Singer, 1984; Lazarus, 1966; Moos \& Billings, 1982). Although there is no single, universally accepted definition of coping, there appears to be an emerging consensus among theoreti-

This research was supported in part by National Institute of Mental Health Grant 1 R01 MH45827-01 to John A. Fairbank.

We wish to thank Juesta Caddell for her helpful comments on a draft of this article.

Correspondence concerning this article should be addressed to John A. Fairbank, Center for Social Research and Policy Analysis, Research Triangle Institute, Post Office Box 12194, Research Triangle Park, North Carolina 27709. cians, clinicians, and researchers alike that cognitions constitute an important component of the individual's adaptation to extremely threatening and traumatic events (see Benner, Roskies, \& Lazarus, 1980; Foa, Steketee, \& Olasov Rothbaum, 1989).

One aspect of cognitive coping that has begun to receive attention is appraisal - the process of evaluating salient dimensions of the stressor event, such as its threat potential, meaningfulness, predictability, and controllability. Cognitive appraisal is proposed to be a primary component of the coping process that may interact with method of coping to affect adjustment to everyday stressors (Folkman \& Lazarus, 1985; Forsythe \& Compas, 1987). A recent advance in the study of extreme events has been the development of conceptual models that emphasize the important role appraisal may play in the development, maintenance, and treatment of PTSD (Chemtob, Roitblat, Hamada, Carlson, \& Twentyman, 1988; Foa et al., 1989; Litz \& Keane, 1989).

Another potentially important dimension of coping is the distinction between problem-focused coping strategies, defined as efforts to recognize, modify, or eliminate the impact of a stressor or cognitive activity, and emotion-focused coping strategies, defined as efforts to regulate emotional states that are associated with or are the result of exposure to stress (Auerbach, 1989; Compas, Malcarne, \& Fondacaro, 1988; Lazarus \& Folkman, 1984). Several studies have examined the relationship between PTSD and the self-reported focus of war veterans' coping efforts. Green et al. (1988) used an inventory developed by Horowitz and Wilner (1980) to study strategies used by Vietnam veterans to cope with their war memories. They found that 
four modes of emotion-focused coping were most associated with a current diagnosis of PTSD: event processing, time out for reflection, religion, and denial. Nezu and Carnevale (1987) studied current coping in Vietnam veterans using scales developed by Billings and Moos (1981) and found that Vietnam veterans with combat-related PTSD were more likely to use emotion-focused coping strategies to manage interpersonal problems than were Vietnam veterans without PTSD. Solomon, Mikulincer, and Flum (1988) used Parkes's (1984) modified version of the Ways of Coping Checklist (Folkman \& Lazarus, 1980) to study coping among young Israeli veterans of the 1982 Lebanon War and found an inverse relationship between number of current PTSD symptoms and the use of problem-focused coping strategies for resolving recent negative life events.

Overall, the results of these studies of war veterans suggest that PTSD is associated with emotion-focused coping strategies. Our study extends previous research on PTSD and coping by (a) assessing how individuals with and without PTSD appraise extreme events, (b) analyzing the coping responses elicited by different chronic stressor conditions, (c) assessing intragroup stability and intergroup variability in coping across different stressor conditions, and (d) examining the types of coping strategies associated with PTSD and resilience in later life.

\section{Method}

\section{Subjects}

Subject recruitment. Three groups of male veterans of World War II (WW II) were recruited to participate in the study: (a) American repatriated prisoners of war (RPWs) with a diagnosis of captivity-related PTSD; (b) RPWs who were exposed to extreme combat, capture, and captivity events but did not meet Diagnostic and Statistical Manual of Mental Disorders (3rd ed., DSM-III; American Psychiatric Association, 1980) criteria for diagnosis of PTSD; and (c) veterans who were not former prisoners of war and who did not experience combat or exposure to other extreme events while in the military (non-RPWs).

RPWs were recruited for the study using a Department of Veterans Affairs data file that listed all former prisoners of war living within a three-county metropolitan area in a southern state. Twenty-two RPWs were randomly selected from this list and recruited by phone, at which time the nature of the study was described. Twenty RPWs agreed to participate for a response rate of $91 \%$. Using the assessment procedure described below, this sample was found to include $10 \mathrm{RPWs}$ with current PTSD and 10 RPWs without PTSD. In addition, a sample of 10 non-RPW veterans were recruited from the community through solicitations to veteran and civic organizations.

Assessment of PTSD. Each subject was initially assessed by a doctoral-level clinical psychologist using a structured clinical interview developed for the assessment of traumatic combat events and specific PTSD symptomatology - the Jackson Structured Interview for PTSD (Keane, Fairbank, Caddell, Zimering, \& Bender, 1985). The version modified for this study included (a) general demographic information; (b) premilitary history; (c) military history; (d) psychiatric history; (e) exposure to combat; (f) a structured PTSD symptom checklist derived from the $D S M-I I I$ criteria; (g) the identification of specific extreme combat, capture, and captivity events; and (h) a structured comprehensive mental status examination to rule out severe cognitive impairment. The interviews, which typically lasted $2 \mathrm{hr}$, emphasized the identification of specific distressing events experienced by each subject during his military service and the determination as to whether these events were traumatic. The structured interviews were also designed to assess the major symptom classes for PTSD found in DSM$I I I$ in relation to the events specified.

PTSD diagnoses were determined in the following way. After each subject had completed the PTSD assessment, the interview data were reviewed independently by a second doctoral-level psychologist. The assessment data for each participant were discussed by the interviewing and reviewing clinicians who then arrived at a consensus regarding the PTSD diagnosis. Consensus agreement on diagnostic group assignment was achieved for all subjects. Next, a blind reliability check on the consensus diagnosis was made on a randomly selected $30 \%$ sample of the subjects. For these cases, a third clinician who was independent of the original diagnostic decision blindly listened to an audiotape of the interview and scored it, using a blank form of the structured interview. Agreement of the independent rater with the consensus diagnosis was $100 \%$.

\section{Procedure}

After administration of the structured clinical interview for PTSD, each subject was asked to complete a battery of self-report instruments assessing current stress and general psychological functioning. While the subject completed this battery, the interviewing clinician reviewed the subject's responses to the combat exposure and extreme events sections of the Jackson Structured Interview for PTSD and compiled a list of the adverse military/captivity experiences described by the respondent. Approximately $5 \mathrm{~min}$ after the subject completed the self-report instruments, the interviewer read the list of events to the respondent, asked him to confirm that these were among his most adverse experiences of WW II, and asked the veteran to identify the most distressing event on the list. The interviewing clinician and subject then discussed the selected event in detail for approximately $5 \mathrm{~min}$, focusing on describing the sequence of the event, the people who were present and their roles, and the subject's reaction at the time. As needed, the clinician probed for clarification in order to ensure adequate exposure to the stressor condition. Next, the subject was asked to complete a selfreport instrument that identified specific responses that he currently used to cope with this memory.

Approximately 15 min after completing the coping inventory in relation to WW II memories, the participant was asked to identify the most distressing ongoing or recent event that he was attempting to handle (e.g., illness of spouse or adult child, retirement). After discussing details of this event with the interviewer for approximately $5 \mathrm{~min}$, the veteran completed a coping inventory with this stressor as the referent. Coping in relation to WW II memories was assessed first in order to foster a logical transition from the immediately preceding structured clinical interview that included extensive discussion of potentially distressing personal war and captivity experiences.

Accompanying each assessment of coping was a form that evaluated the subject's appraisal of the current impact of the stressor in terms of perceived meaningfulness, control, predictability, and the amount of stress associated with occurrence of the referent event. Each group was subsequently compared on (a) demographic and background variables; (b) measures of stress, appraisal, and adjustment; and (c) strategies used to cope with specific memories of captivity/military experiences and current stressors.

\section{Dependent Variables}

Measures of general psychological stress and adjustment. This battery included (a) a 49-item, empirically derived Minnesota Multiphasic Personality Inventory (MMPI) PTSD scale (Keane, Malloy, \& Fairbank, 1984); (b) the Symptom Checklist-90-Revised (SCL-90-R; Derogatis, 1977), a 90-item inventory of current symptoms of psychopa- 
thology; (c) the Daily Hassles Scale (Kanner, Coyne, Schaefer, \& Lazarus, 1981), a 117-item inventory of hassles and irritants; (d) the General Well-Being Schedule (Fazio, 1977), a 25-item questionnaire regarding health and mental health; and (e) the Life Experiences Survey (LES; Sarason, Johnson, \& Siegel, 1978), a 47-item inventory of occurrence and impact of major life events.

Appraisal measures. To assess the degree to which subjects appraised stressor conditions as psychologically threatening and meaningful, we asked subjects to rate each in terms of its current significance, the efficacy of self-management (control), predictability of onset, and the amount of stress associated with its occurrence. Specifically, subjects rated the significance ("How meaningful is this memory/problem to you?") of each event on a 7-point scale from very meaning ful (1) to has no meaning (7). Level of perceived control over WW II memories and current life stressors was assessed by the question "How much control do you have over this memory/event?" Ratings were made on a 7-point scale from no control (1) to total control (7).

To assess predictability, subjects were asked, "How easy is it to predict or tell when this memory/problem is going to happen or get worse?" Responses were rated on a 7-point scale from very difficult (1) to very easy (7). Subjects appraised the level of stress associated with each memory/event by responding to the following statement: "If 0 represented no stress at all and 100 represented the amount of stress that a person would feel if a close friend or family member would die suddenly and unexpectedly, write in a number that represents the amount of stress that you feel for this problem."

Coping measures. Efforts at coping were assessed using the Ways of Coping Checklist-Revised (WOC-R; Lazarus \& Folkman, 1984), the most widely used measure of adult coping (Auerbach, 1989). This 66item inventory comprises five empirically derived scales (Problem-Focused Coping, Wishful Thinking, Detachment, Seeking Social Support, and Focusing on the Positive) and three rationally derived scales (Self-Blame, Tension Reduction, and Keeping to Self). Applicable items are rated on a 4-point scale of frequency of use from not used (0) to used a great deal (3).

\section{Results}

\section{Demographic and Background Variables}

The groups were compared on a variety of important demographic and military history variables through univariate analyses of variance (ANOVAs) with subsequent Duncan's multiplerange test comparisons (see Table 1). The ANOVA for age was significant, and Duncan comparisons indicated that the non-
RPW group was significantly older than the two RPW groups. This may be related to their noncombat status because these veterans were older when WW II began and as a result were possibly in the service longer before the war and more likely to be assigned to noncombat administrative, training, or service support roles. The ANOVAs for age when began military service, education, income, months in service, and number of months in captivity were not significant. Comparison on these demographic and background variables demonstrated the similarity of the groups, with the exception of age.

\section{Current Psychological Functioning and Treatment History}

The groups were compared on a variety of clinical assessment inventories to obtain additional information regarding current psychological functioning (see Table 2). ANOVAs for the MMPI PTSD scale and the General Well-Being Schedule were significant. As expected, the RPWs with PTSD received significantly higher scores on the PTSD scale than did the other two groups. The RPWs with PTSD received significantly lower scores than did the other groups on the General Well-Being Schedule, where a high score is indicative of psychological adjustment. A multivariate analysis of variance (MANOVA) for the global indices of the SCL-90-R was significant, $F(6,52)=$ $4.72, p<.0007$, as were the subsequent ANOVAs. The RPWs with PTSD received significantly higher scores on the Global Severity Index (GSI), the Positive Symptom Distress Index (PSDI), and the Positive Symptom Total (PST). A MANOVA for the Hassles Scale was significant, $F(4,52)=4.61, p<.003$, as were the subsequent ANOVAs. Results indicate that the RPWs with PTSD had higher number and severity of hassles. A MANOVA for the number and impact of positive and negative life events during the past year on the LES was not significant, $F(8,48)=1.04, p<.422$. Overall, the assessment inventories further demonstrated the impaired psychological functioning of the RPWs with PTSD.

Regarding psychiatric history, 7 R PWs with PTSD reported that they had sought treatment for psychological or emotional distress on at least one occasion since entering the military. One subject in the group of RPWs without PTSD and none of the non-RPWs reported ever having received services for psycholog-

Table 1

Means, Standard Deviations, Analyses of Variance, and Duncan Comparisons of Demographics

\begin{tabular}{|c|c|c|c|c|c|c|c|c|}
\hline \multirow[b]{2}{*}{ Variable } & \multicolumn{2}{|c|}{$\begin{array}{l}\text { RPWs with } \\
\text { PTSD }\end{array}$} & \multicolumn{2}{|c|}{$\begin{array}{l}\text { RPWs without } \\
\text { PTSD }\end{array}$} & \multicolumn{2}{|c|}{ Non-RPWs } & \multirow[b]{2}{*}{$F$} & \multirow[b]{2}{*}{$d f$} \\
\hline & $M$ & $S D$ & $M$ & $S D$ & $M$ & $S D$ & & \\
\hline Age (in years) & $63.2_{\mathrm{a}}$ & 1.99 & $62.7 \mathrm{a}$ & 2.83 & $67.2_{\mathrm{b}}$ & 6.01 & $3.79^{*}$ & 2,27 \\
\hline Education (in years) & $12.3^{\mathrm{a}}$ & 4.30 & $14.4^{\mathrm{a}}$ & 2.91 & 16.1 & 2.32 & 3.16 & 2,26 \\
\hline Income (in thousands) & 26.9 & 32.91 & 41.4 & 27.05 & 34.2 & 12.54 & 0.57 & 2,18 \\
\hline Age began service (in years) & 20.2 & 1.40 & 21.7 & 4.35 & 24.7 & 6.10 & 2.60 & 2,26 \\
\hline Months in service & 42.1 & 24.17 & 90.5 & 129.97 & 51.2 & 42.61 & 0.99 & 2,26 \\
\hline Months as a POW & 15.1 & 15.16 & 10.5 & 7.16 & na & & 0.74 & 1,18 \\
\hline
\end{tabular}

Note. $\mathrm{RPW}=$ repatriated prisoner of war; $\mathrm{PTSD}=$ posttraumatic stress disorder $; \mathrm{POW}=$ prisoner of war; $n a=$ not applicable. Means having the same subscript are not significantly different.

$* p<.04$. 
Table 2

Means, Standard Deviations, Analyses of Variance, and Duncan Comparisons of Assessment Inventories

\begin{tabular}{|c|c|c|c|c|c|c|c|c|}
\hline \multirow[b]{2}{*}{ Measure } & \multicolumn{2}{|c|}{$\begin{array}{l}\text { RPWs with } \\
\text { PTSD }\end{array}$} & \multicolumn{2}{|c|}{$\begin{array}{l}\text { RPWs without } \\
\text { PTSD }\end{array}$} & \multicolumn{2}{|c|}{ Non-RPWs } & \multirow[b]{2}{*}{$F$} & \multirow[b]{2}{*}{$d f$} \\
\hline & $M$ & $S D$ & $M$ & $S D$ & $M$ & $S D$ & & \\
\hline $\begin{array}{l}\text { MMPI: PTSD scale } \\
\text { General Well-Being }\end{array}$ & $25.8_{\mathrm{a}}$ & 10.58 & $9.1_{\mathrm{b}}$ & 8.52 & $2.7_{b}$ & 1.83 & $22.72^{* *}$ & 2,27 \\
\hline Schedule & $61.9 \mathrm{a}$ & 13.27 & $88.5_{b}$ & 23.24 & $100.7_{b}$ & 6.91 & $13.35^{* *}$ & 2,27 \\
\hline SCL-90-R: GSI & $1.45_{\mathrm{a}}$ & 0.37 & 0.59 & 0.39 & $0.31_{b}$ & 0.21 & $31.59^{* *}$ & 2,27 \\
\hline SCL-90-R: PSDI & $2.17_{\mathrm{a}}$ & 0.46 & $1.52 \mathrm{~b}$ & 0.40 & $1.3 l_{\mathrm{b}}$ & 0.31 & $13.18^{* *}$ & 2,27 \\
\hline SCL-90-R: PST & $60.2_{\mathrm{a}}$ & 11.81 & $32.6_{\mathrm{b}}$ & 16.19 & $23.4_{b}$ & 17.03 & $15.91^{* *}$ & 2,27 \\
\hline Hassles: No. & $30.7_{\mathrm{a}}^{\mathrm{a}}$ & 18.32 & $13.4_{b}$ & 10.67 & $11.0_{\mathrm{b}}$ & 6.34 & $6.91^{*}$ & 2,26 \\
\hline $\begin{array}{l}\text { Hassles: Severity } \\
\text { LES: No. of positive }\end{array}$ & $52.4_{\mathrm{a}}$ & 28.67 & $16.9_{\mathrm{b}}$ & 13.87 & $12.8_{\mathrm{b}}$ & 7.21 & $13.33^{* *}$ & 2,26 \\
\hline $\begin{array}{l}\text { experiences } \\
\text { LES: Impact of positive }\end{array}$ & 2.0 & 3.27 & 1.9 & 2.42 & 1.9 & 2.08 & 0.01 & 2,26 \\
\hline $\begin{array}{l}\text { experiences } \\
\text { LES: No. of negative }\end{array}$ & 5.4 & 9.25 & 2.6 & 2.55 & 3.4 & 3.95 & 0.56 & 2,26 \\
\hline $\begin{array}{l}\text { experiences } \\
\text { LES: Impact of negative }\end{array}$ & 4.1 & 4.15 & 2.1 & 2.52 & 1.4 & 1.58 & 2.22 & 2,26 \\
\hline experiences & 9.8 & 12.04 & 4.0 & 6.18 & 2.3 & 2.95 & 2.36 & 2,26 \\
\hline
\end{tabular}

Note. $\quad \mathrm{RPW}=$ repatriated prisoner of war; $\mathrm{PTSD}=$ posttraumatic stress disorder; $\mathrm{MMPI}=$ Minnesota Multiphasic Personality Inventory; SCL-90-R = Symptom Checklist-90-Revised; GSI = Global Severity Index; PSDI = Positive Symptom Distress Index; Hassles = Daily Hassles Scale; PST = Positive Symptom Total; LES $=$ Life Experiences Survey. Means having the same subscript are not significantly different. ${ }^{*} p<.0039$. ${ }^{* *} p<.0001$.

ical problems. RPWs with PTSD reported receiving treatment for a range of Axis I disorders (e.g., depression, PTSD, alcohol abuse or dependence) as well as nonspecific psychological distress (e.g., anxiety, nervousness). Frequency and recency of use of services also varied greatly, ranging from a single session with a military psychiatrist in 1945 for the one RPW without PTSD who reported receiving services to regularly scheduled outpatient sessions over a course of several years for one RPW with PTSD.

\section{Stressor Appraisal Variables}

A MANOVA for the stressor appraisal measures of ongoing memories of WW II captivity/military experiences was significant, $F(8,48)=5.90, p<.0001$. The subsequent ANOVAs were significant for all appraisal variables (see Table 3). Both groups of RPWs reported that their captivity memories were signifcantly more meaningful and stressful than the war memories of veterans who did not experience capture (i.e., non-RPWs). RPWs with PTSD reported significantly less control over the impact of these memories than did RPWs without PTSD and non-RPWs. In addition, RPWs with PTSD reported significantly less ability to predict the onset and severity of WW II memories than did their non-RPW counterparts. In contrast to WW II memories, a MANOVA revealed no significant between-groups differences in appraisal of the meaningfulness, control, predictability, and stress of recent or current stressors, $F(8,48)=0.71, p<.683$.

\section{Internal Consistency of the Coping Measures}

To determine the degree of internal consistency of the WOC$\mathrm{R}$ scales, Cronbach's alpha and item-total correlations were computed for each scale for both WW II memories and recent stressors. For memories of WW II, alpha coefficients ranged from .493 to $.942,(M=.694)$, and mean item-total correlations ranged from .640 to .807 . For recent stressors, alpha coefficients ranged from .529 to $.891(M=.708)$, and mean item-total correlations ranged from .621 to .795 . The results indicate sufficient internal consistency for each scale.

\section{Coping with Memories of Captivity/Military}

A MANOVA for WOC-R scales for coping with WW II memories was significant, $F(16,42)=2.66, p<.006$. As indicated in Table 4, subsequent ANOVAs indicated significant differences for each of the WOC-R scales. The RPWs with PTSD used wishful thinking, self-blame, self-isolation, and seeking social support significantly more than did the RPWs without PTSD and the non-RPW veterans. The RPWs with PTSD also used significantly more problem-focused coping, distancing, emphasizing the positive, and tension reduction than did the nonRPW group. The RPWs without PTSD used significantly more wishful thinking, emphasizing the positive, and tension reduction than did the non-RPW group of veterans.

\section{Coping with Current Life Stressors}

A MANOVA for the WOC-R scales for coping with a current stressor was not significant, $F(16,42)=1.34, p<.221$. Group means and standard deviations are presented in Table 5. Although the differences were not significant, the RPWs with PTSD tended toward using more wishful thinking, self-blame, 
Table 3

Means, Standard Deviations, Analyses of Variance, and Duncan Comparisons of Appraisal Measures of World War II Memories and Recent Stressors

\begin{tabular}{|c|c|c|c|c|c|c|c|c|c|}
\hline \multirow{2}{*}{$\begin{array}{c}\text { Condition } \\
\text { and variable }\end{array}$} & \multicolumn{2}{|c|}{$\begin{array}{l}\text { RPWs with } \\
\text { PTSD }\end{array}$} & \multicolumn{2}{|c|}{$\begin{array}{c}\text { RPWs } \\
\text { without } \\
\text { PTSD }\end{array}$} & \multicolumn{2}{|c|}{ Non-RPWs } & \multirow[b]{2}{*}{$F$} & \multirow[b]{2}{*}{$d f$} & \multirow[b]{2}{*}{$p<$} \\
\hline & $M$ & $S D$ & $M$ & $S D$ & $M$ & $S D$ & & & \\
\hline \multicolumn{10}{|c|}{ World War II memories } \\
\hline Significance & $2.6_{a}$ & 1.71 & $3.6_{\mathrm{a}}$ & 2.45 & $6.5_{b}$ & 1.27 & 11.75 & 2,26 & .0002 \\
\hline Stress & $67.8_{\mathrm{a}}$ & 36.58 & $44.0_{\mathrm{a}}$ & 35.26 & $11.7_{b}$ & 25.73 & 7.05 & 2,26 & .0036 \\
\hline Control & $3.0_{\mathrm{a}}$ & 1.63 & 5.7 & 1.34 & $5.7_{\mathrm{b}}$ & 2.06 & 7.52 & 2,26 & .0026 \\
\hline Predictability & $2.7_{\mathrm{a}}$ & 1.95 & $3.6_{\mathrm{ab}}$ & 2.22 & $5.5_{\mathrm{b}}$ & 2.55 & 4.52 & 2,26 & .021 \\
\hline \multicolumn{10}{|l|}{ Recent stressors } \\
\hline Significance & 2.5 & 1.65 & 3.5 & 2.42 & 2.6 & 2.22 & 1.07 & 2,26 & $n s$ \\
\hline Stress & 79.0 & 22.21 & 59.5 & 28.03 & 68.0 & 36.53 & 1.20 & 2,26 & $n s$ \\
\hline Control & 3.0 & 1.63 & 4.3 & 2.45 & 3.8 & 2.86 & 0.49 & 2,26 & ns \\
\hline Predictability & 3.9 & 2.38 & 4.0 & 2.50 & 3.3 & 2.83 & 0.21 & 2,26 & ns \\
\hline
\end{tabular}

Note. $\mathrm{RPW}=$ repatriated prisoner of war; $\mathrm{PTSD}=$ posttraumatic stress disorder. Means having the same subscript are not significantly different.

and self-isolation than did the RPWs without PTSD and the non-RPW veterans.

\section{Relative Use of WOC-R Scales}

To facilitate understanding of the relative use of the various methods of coping, the relative ordering of the scores on each WOC-R scale should be considered (see means in Tables 4 and 5). Several important differences between the groups are evident. It is clear that for captivity/military memories, the RPW with PTSD group used more coping strategies and used them to a greater degree than did the other groups. Also, it appears that some cognitive coping strategies were less effective than others for coping with memories of captivity. For instance, the RPWs with PTSD used self-isolation and wishful thinking much more frequently than did the RPWs without PTSD. In contrast, the RPWs without PTSD used emphasizing the posi- tive and distancing more frequently than other coping strategies. The non-RPW veterans rarely used cognitive coping strategies to deal with WW II memories.

For recent stressors, the RPWs with PTSD also used more of the coping strategies, and to a greater degree, than did the other groups. Again, RPWs with PTSD reported using self-isolation and wishful thinking more than other coping strategies and more than did the other two groups. The RPWs without PTSD reported using emphasizing the positive, self-isolation, and problem-focused coping more frequently than other coping strategies. Problem-focused coping and seeking social support were the coping strategies most often used by the non-RPW veterans.

\section{Discussion}

Our findings revealed several differences between RPWs with PTSD, RPWs without PTSD, and noncombat veterans

Table 4

Means, Standard Deviations, Analyses of Variance, and Duncan Comparisons of Scores on Ways of Coping-Revised Scale: World War II Memories

\begin{tabular}{|c|c|c|c|c|c|c|c|c|c|}
\hline \multirow[b]{2}{*}{ Strategy } & \multicolumn{2}{|c|}{$\begin{array}{l}\text { RPWs with } \\
\text { PTSD }\end{array}$} & \multicolumn{2}{|c|}{$\begin{array}{c}\text { RPWs } \\
\text { without } \\
\text { PTSD }\end{array}$} & \multicolumn{2}{|c|}{ Non-RPWs } & \multirow[b]{2}{*}{$F$} & \multirow[b]{2}{*}{$d f$} & \multirow[b]{2}{*}{$p<$} \\
\hline & $M$ & $S D$ & $M$ & $S D$ & $M$ & $S D$ & & & \\
\hline Problem-focused coping & $1.50_{\mathrm{a}}$ & 0.65 & $0.82_{\mathrm{ab}}$ & 0.75 & $0.34_{b}$ & 0.94 & 5.47 & 2,27 & .01 \\
\hline Wishful thinking & $1.56_{\mathrm{a}}$ & 0.62 & $0.55_{b}$ & 0.63 & $0.06_{c}^{\circ}$ & 0.13 & 21.96 & 2,27 & .0001 \\
\hline Distancing & 1.33 & 0.47 & $0.97_{\mathrm{b}}$ & 0.80 & $0.57^{c}$ & 0.65 & 3.45 & 2,27 & .0462 \\
\hline Emphasizing the positive & $1.53_{\mathrm{a}}$ & 0.83 & $1.20_{\mathrm{a}}$ & 1.09 & $0.28_{\mathrm{b}}$ & 0.36 & 6.28 & 2,27 & .0058 \\
\hline Self-blame & $1.13_{\mathrm{a}}$ & 0.61 & $0.30_{\mathrm{b}}$ & 0.40 & $0.10^{\circ}$ & 0.32 & 14.20 & 2,27 & .0001 \\
\hline Tension reduction & $0.67 \mathrm{a}$ & 0.59 & $0.47 \mathrm{a}$ & 0.48 & $0.03_{\mathrm{b}}$ & 0.11 & 8.85 & 2,27 & .0011 \\
\hline Self-isolation & $1.70_{\mathrm{a}}^{\mathrm{a}}$ & 0.51 & $0.93_{\mathrm{b}}$ & 0.77 & $0.37^{\circ}$ & 0.66 & 10.52 & 2,27 & .0004 \\
\hline Seeking social support & $1.36_{\mathrm{a}}$ & 0.65 & $0.56_{\mathrm{b}}$ & 0.41 & $0.20_{\mathrm{b}}$ & 0.24 & 16.14 & 2,27 & .0001 \\
\hline
\end{tabular}

Note. $\mathrm{RPW}=$ repatriated prisoner of war; $\mathrm{PTSD}=$ posttraumatic stress disorder. Means having the same subscript are not significantly different. 
Table 5

Means and Standard Deviations for Scores on Ways of Coping-Revised Scale: Recent Stressors

\begin{tabular}{|c|c|c|c|c|c|c|}
\hline \multirow[b]{2}{*}{ Strategy } & \multicolumn{2}{|c|}{$\begin{array}{l}\text { RPWs with } \\
\text { PTSD }\end{array}$} & \multicolumn{2}{|c|}{$\begin{array}{l}\text { RPWs without } \\
\text { PTSD } \\
\end{array}$} & \multicolumn{2}{|c|}{ Non-RPWs } \\
\hline & $M$ & $S D$ & $M$ & $S D$ & $M$ & $S D$ \\
\hline Problem-focused coping & 1.75 & 0.39 & 1.28 & 0.69 & 1.00 & 1.03 \\
\hline Wishful thinking & 1.90 & 0.87 & 0.98 & 0.85 & 0.64 & 0.70 \\
\hline Distancing & 1.27 & 0.70 & 1.20 & 0.61 & 0.65 & 0.40 \\
\hline Emphasizing the positive & 1.58 & 0.66 & 1.33 & 0.91 & 0.78 & 0.69 \\
\hline Self-blame & 1.27 & 0.64 & 0.67 & 0.68 & 0.40 & 0.52 \\
\hline Tension reduction & 0.87 & 0.76 & 0.63 & 0.71 & 0.40 & 0.62 \\
\hline Self-isolation & 1.97 & 0.55 & 1.30 & 0.81 & 0.63 & 0.73 \\
\hline Seeking social support & 1.56 & 0.66 & 1.01 & 0.79 & 0.90 & 0.72 \\
\hline
\end{tabular}

Note. Because multivariate analysis of variance was not significant, subsequent analyses were not performed. RPW = repatriated prisoner of war; PTSD = posttraumatic stress disorder.

from WW II in terms of psychological adjustment, cognitive appraisal of stressors, and coping responses to these stressors. RPWs with a diagnosis of PTSD reported higher levels of psychological distress and poorer psychological adjustment than did both the RPWs without PTSD and noncombat veteran groups. Higher scores on the PTSD MMPI scale, higher number and severity of SCL-90-R symptoms and hassles on the Hassles Scale, and lower scores on the General Well-Being Schedule all corroborate with the PTSD diagnosis as well as bespeak the continuing psychological problems of WW II RPWs who meet diagnostic criteria for PTSD. These differences were not associated with current or recent environmental stressors as the three groups did not significantly differ in their report of the number and severity of recent major life events as measured by the LES. Overall, these findings are consistent with data from the National Vietnam Veterans Readjustment Study (Kulka et al., 1990), which found that Vietnam veterans with chronic PTSD were more impaired across a variety of indicators of adjustment than were comparison groups of veterans and civilians without PTSD.

The WW II memories reported by both RPWs with and without PTSD were uniformly traumatic, whereas those reported by the noncombat veterans were not. Correspondingly, both groups of RPWs similarly appraised their WW II memories as more significant and stressful compared with the significance and stressfulness ascribed by the noncombat veterans to their WW II memories. However, whereas both the PTSD and well-adjusted RPWs were equivalent in their appraisal of the predictability of the WW II memories, the RPWs with PTSD appraised their WW II memories as being more uncontrollable. These findings are supportive of Foa et al.'s (1989) hypothesis that perceived controllability is a critical cognitive factor in human adaptation to extreme events. On the basis of the findings of their review of animal and human experimental studies on the relationship of predictability and controllability of stressor events to adaptation, Foa et al.(1989) proposed that controllability may play an even more pivotal role than predictability in determining PTSD outcomes. The present findings offer some empirical support for this hypothesis regarding the relationship of perceived controllability to PTSD adaptations.

All three groups were equivalent in ratings of cognitive ap- praisal variables associated with current stressors. This finding suggests that neither exposure to extreme events nor PTSD diagnosis was associated with appraisal differences in the perceived significance, stressfulness, controllability, or predictability of the more recent stressor events.

Significant differences were found between the groups in terms of how they reported coping with WW II memories. In general, RPWs with PTSD used a greater multiplicity of coping behaviors and used these coping behaviors more frequently than did RPWs who were similarly exposed to extreme events but who were currently well adjusted. Regarding specific coping strategies, RPWs with PTSD used wishful thinking, selfblame, self-isolation, and seeking social support more frequently than did RPWs without PTSD. This finding is consistent with other research showing strong relationships between psychopathology and ineffective avoidance coping in other populations, such as individuals with psychological difficulties and coronary heart disease (e.g., Vitaliano, Katon, Maiuro, \& Russo, 1989). There were no significant differences between the RPW groups in the use of problem-focused coping, distancing, emphasizing the positive, and tension reduction.

No significant group differences were found in reported coping with recent stressors-a finding possibly attributable to the small size of our group samples. However, it is noteworthy that despite their size, our samples were sufficient to detect group differences in coping responses to WW II memories, attesting to the robust nature of coping differences related to exposure to extreme events and the presence of PTSD symptomatology. The employment of larger samples from these populations in future studies may detect less robust yet significant differences in coping related to recent stressors.

With respect to our finding of no significant intergroup variability in coping with recent stressors, we note that this assessment always followed the assessment of coping with WW II memories. Although we are not aware of any literature that suggests that a coping assessment for one stressor would have a systematic influence on subsequent assessments, future research might examine this issue further by changing the order of presentation of the different siressor conditions or by making the stressor assessments more independent. The latter approach could be accomplished by scheduling larger blocks of 
time between assessment conditions or by conducting the assessments on separate days.

A comparison of the three groups in terms of the most frequently reported coping response as measured by the WOC-R scales revealed suggestive findings that, if replicated by future studies, might serve toward explaining the perseverance of coping difficulties associated with PTSD. In dealing with the memory of extreme events from WW II, RPWs with PTSD most frequently employed self-isolation-a behavioral response frequently observed among individuals afflicted with PTSD. Furthermore, self-isolation ranked first for RPWs with PTSD as the most frequently used coping response for recent stressors as well.

Although RPWS without PTSD were similarly exposed to extreme events, their most frequently reported coping response to WW II memories differed from their PTSD counterparts. Well-adjusted RPWs most frequently used emphasizing the positive-a coping response that serves an emotional regulatory function by means of cognitively reappraising the event. This may help in understanding why although both RPWs with PTSD and well-adjusted RPWs similarly reported that memories of traumatic experiences were unpredictable, the well-adjusted RPWs reported having more control over them. Emphasizing the positive appears to have more promise as a coping response that can exert control through cognitive reappraisal over an unpredictable memory of a trauma that as a historical event cannot itself be altered. On the other hand, self-isolation does not lend itself as an effective way of exerting control over these unpredictable WW II memories.

Interestingly, just as the RPWs with PTSD used the same response (viz., self-isolation) as their most frequently utilized coping effort for both WW II memories and recent stressors, the RPWs without PTSD similarly reported using most frequently the same coping behavior-in their case, however, emphasizing the positive-for recent stressors as they did for the WW II memories. The noncombat veterans, on the other hand, showed no similarity in type or pattern of coping across WW II memories and recent stressors.

This similarity in transsituational pattern but difference in content among coping behaviors observed for both groups of RPWs, but not for nontraumatized veterans, leads to speculation about the nature of long-term coping among these populations. Inasmuch as both groups of RPWs have had a long history of coping with traumatic WW II memories, it is possible that they have developed a characteristic or preferred coping response to stressors. This possibility would appear to be inconsistent with a prevailing view of coping as a fluid, stressorspecific phenomenon as opposed to a stable, traitlike coping style (see Folkman \& Lazarus, 1985). However, a possible exception to this common observation of the fluid, stressor-specific nature of coping may be found among those who have been exposed to extreme events.

One plausible explanation for these observations may be found in the nature of the stressor itself. The extreme nature of captivity-related events may have severely restricted the range and fluid responsivity of perceptual and behavioral responses of RPWs, thus promoting a highly practiced, rigid, automatic or characteristic pattern of coping responses that survivors of extreme events are likely to use later to other stressors--stressors that may or may not be more amenable to quite different types or patterns of coping responses. Some coping responses, such as emphasizing the positive, may be relatively universal in their efficacy across a broad range of stressors. Other coping responses, such as self-isolation, may not enjoy such broad applicability. The extent to which chronic maladaptive coping in persons with PTSD can be changed is an empirical question of interest to clinicians who provide treatment services to survivor populations. This important issue should be addressed in future research.

This study has identified several potentially important observed similarities and differences between RPWs with chronic PTSD, RPWs without PTSD, and noncombat (and nontraumatized) veterans in terms of stressors, psychological adjustment, and long-term coping. As surviving combat veterans from WW II are reaching life stages wherein they are encountering new and increasing stressors associated with aging, retirement, and loss of family and friends, such information is critical for developing valid and useful strategies for modifying long-term coping in trauma survivors.

\section{References}

American Psychiatric Association. (1980). Diagnostic and statistical manual of mental disorders (3rd ed.). Washington, DC: Author.

Auerbach, S. M. (1989). Stress management and coping research in the health care setting: An overview and methodological commentary. Journal of Consulting and Clinical Psychology, 57, 388-395.

Benner, P., Roskies, E., \& Lazarus, R. S. (1980). Stress and coping under extreme conditions. In J. E. Dimsdale (Ed.), Survivors, victims, and perpetrators: Essays on the Nazi holocaust (pp. 219-258). Washington, DC: Hemisphere.

Billings, A. G., \& Moos, R. H. (1981). The role of coping responses and social resources in attenuating the stress of life events. Journal of Behavioral Medicine, 4, 139-157.

Chemtob, C., Roitblat, H. L., Hamada, R. S., Carlson, J. G., \& Twentyman, C. T. (1988). A cognitive action theory of post-traumatic stress disorder. Journal of Anxiety Disorders, 2, 253-275.

Compas, B. E., Malcarne, V. L., \& Fondacaro, K. M. (1988). Coping with stressful events in older children and young adolescents. Journal of Consulting and Clinical Psychology, 56, 405-411.

Derogatis, L. R. (1977). SCL-90-R: Administration, scoring and procedures manual-II. Towson, MD: Clinical Psychometric Research.

Elder, G. H., \& Clipp, E. C. (1989). Combat experience and emotional health: Impairment and resilience in later life. Journal of Personality, $57,311-341$

Fairbank, J. A., \& Nicholson, R. A. (1987). Theoretical and empirical issues in the treatment of post-traumatic stress disorder in Vietnam veterans. Journal of Clinical Psychology, 43, 44-55.

Fazio, A. F. (1977). A concurrent validational study of the NCHS General Well-Being Schedule (DHEW Publication No. HRA 78-1347). Washington, DC: U.S. Department of Health, Education, and Welfare.

Fleming, R., Baum, A., \& Singer, J. E. (1984). Toward an integrative approach to the study of stress. Journal of Personality and Social Psychology, 46, 939-949.

Foa, E. B., Steketee, G., \& Olasov Rothbaum, B. (1989). Behavioral/cognitive conceptualizations of post-traumatic stress disorder. Behavior Therapy, 20, 155-176.

Folkman, S., \& Lazarus, R. S. (1980). An analysis of coping in a middleaged community sample. Journal of Health and Social Behavior, 2I, 219-239.

Folkman, S., \& Lazarus, R. S. (1985). If it changes it must be a process: Study of emotion and coping during three stages of a college examination. Journal of Personality and Social Psychology, 48, 150-170.

Forsythe, C. J., \& Compas, B. E. (1987). Interaction of cognitive ap- 
praisals of stressful events and coping: Testing the goodness of fit hypothesis. Cognitive Therapy and Research, 11, 473-485.

Green, B. L., Lindy, J. D., \& Grace, M. C. (1988). Long-term coping with combat stress. Journal of Traumatic Stress, 1, 399-412.

Horowitz, M. J., \& Wilner, N. (1980). Life events, stress, and coping. In L. Poon (Ed.), Aging in the 1980's. Washington, DC: American Psychiatric Association.

Kanner, A. D., Coyne, J., Schaefer, C., \& Lazarus, R. S. (1981). Comparison of two modes of stress measurement: Daily hassles and uplifts versus major events. Journal of Behavioral Medicine, 4, 1-39.

Keane, T. M., Malloy, P. F., \& Fairbank, J. A. (1984). Empirical development of an MMPI subscale for the assessment of combat-related posttraumatic stress disorder. Journal of Consulting and Clinical Psychology, 52, 888-891.

Keane, T. M., Fairbank, J. A., Caddell, J. M., Zimering, R. T., \& Bender, M. E. (1985). A behavioral approach to assessing and treating posttraumatic stress disorders in Vietnam veterans. In C. R. Figley (Ed.), Trauma and its wake: The assessment and treatment of posttraumatic stress disorders (pp. 257-294). New York: Brunner/Mazel.

Kulka, R. A., Schlenger, W. E., Fairbank, J. A., Hough, R. L., Jordan, B. K., Marmar, C. R., \& Weiss, D. S. (1990). Trauma and the Vietnam generation. New York: Brunner/Mazel.

Lazarus, R. S. (1966). Psychological stress and the coping process. New York: McGraw-Hill.

Lazarus, R. S., \& Folkman, S. (1984). Stress, appraisal, and coping. New York: Springer.
Litz, B. T., \& Keane, T. M. (1989). Information processing in anxiety disorders: Application to the understanding of post-traumatic stress disorder. Clinical Psychology Review, 9, 243-257.

Moos, R., \& Billings, A. (1982). Conceptualizing and measuring coping resources and processes. In L. Goldberger \& S. Breznitz (Eds.), Handbook of stress: Theoretical and clinical aspects (pp. 212-230). New York: Macmillan.

Nezu, A. M., \& Carnevale, G. J. (1987). Interpersonal problem solving and coping reactions of Vietnam veterans with posttraumatic stress disorder. Journal of Abnormal Psychology, 96, 155-157.

Parkes, K. R. (1984). Locus of control, cognitive appraisal, and coping in stressful episodes. Journal of Personality and Social Psychology, 46, 655-668.

Sarason, I. G., Johnson, J. H., \& Siegel, J. M. (1978). Assessing the impact of life changes: Development of the Life Experiences Survey. Journal of Consulting and Clinical Psychology, 46, 932-946.

Solomon, Z., Mikulincer, M., \& Flum, H. (1988). Negative life events, coping responses, and combat-related psychopathology: A prospective study. Journal of Abnormal Psychology, 97, 302-307.

Vitaliano, P. P., Katon, W., Maiuro, R. D., \& Russo, J. (1989). Coping in chest pain patients with and without psychiatric disorders. Journal of Consulting and Clinical Psychology, 57, 338-343.

Received February 13, 1990 Revision received August 24, 1990 Accepted August 28, 1990 